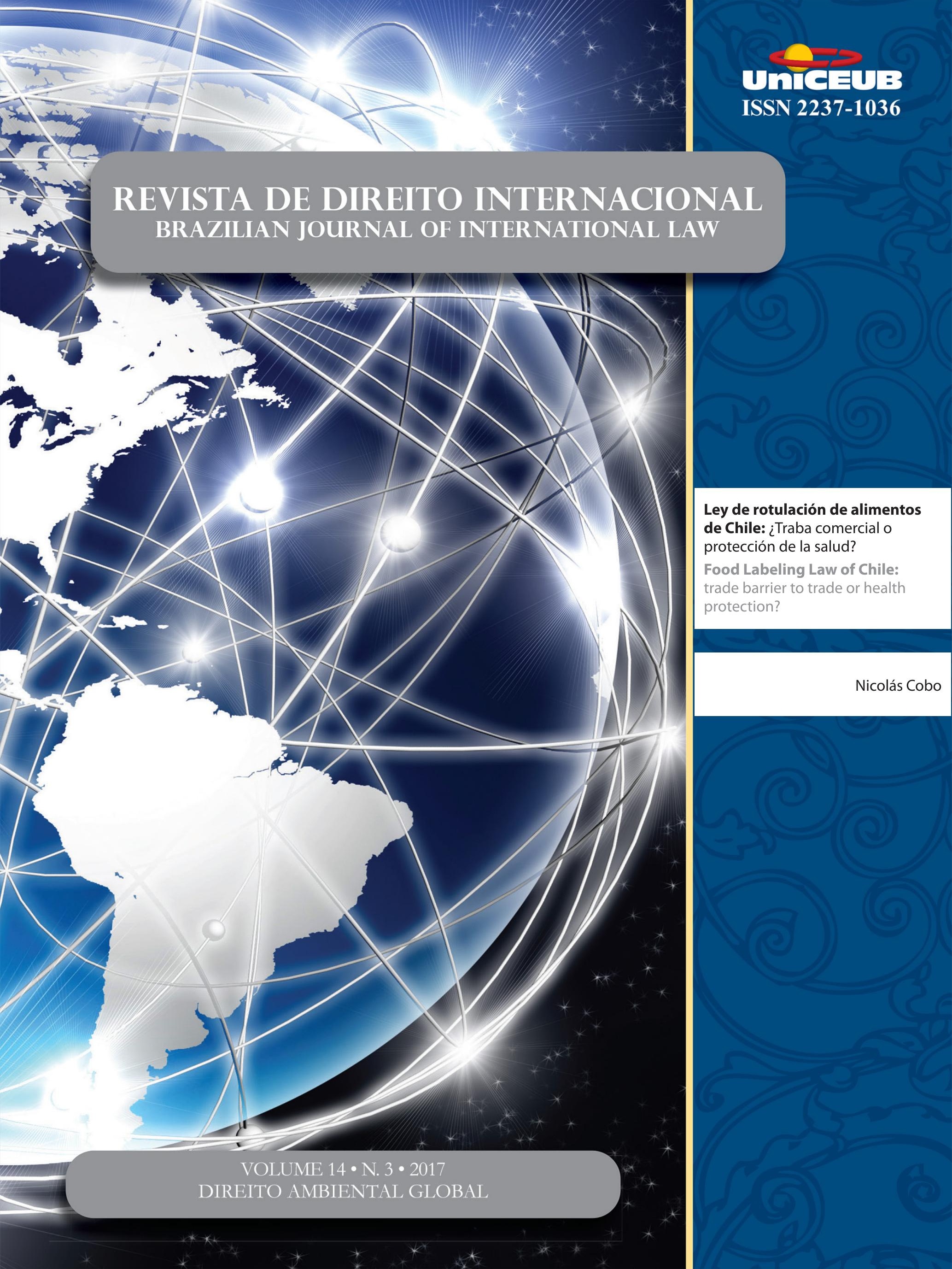




\section{Sumário}

I. Crônicas do Direito Internacional ...............................................1

CRÔNICAS DE DiREITO INTERNACIONAL PÚBLICO ........................................................................ 3

A política australiana de Refúgio e a decisão da Suprema Corte de PAPUA NOVA GUINÉ: A



Tarin Cristino Frota Mont'Alverne e Ana Carolina Barbosa Pereira Matos

II. Dossiê especial: Direito Ambiental Global............................................ 7

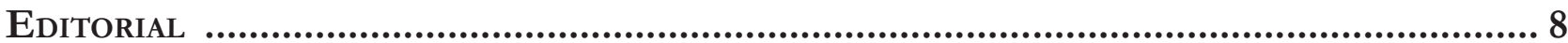

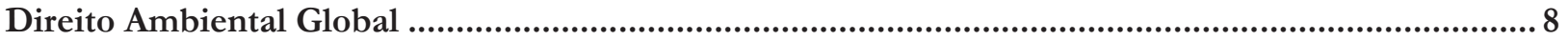

Priscila Pereira de Andrade

Direito Global: UMa TEORIA ADEQUAda PARA SE PENSAR o DiREITO AMBIENTAL? ................10 Arnaud Van Waeyenberge

“Complex is Beautiful": What role for the 2015 Paris Agreement in making the Effective Links within the Climate Regime Complex? .................................................21 Sandrine Maljean-Dubois e Matthieu Wemaëre

UNE ILLUSTRATION DU DROIT GLOBAL, LA LEX MERCATORIA CLIMATIQUE...............................31 Mathilde Hautereau-Boutonnet

OCÉANS ET CHANGEMENTS CLIMATIQUES : RECHERCHER LES INTERACTIONS AU SEIN DE LA FRAGMENTATION DU DROIT INTERNATIONAL

Sophie Gambardella

Une gouvernance globale du Climat par la transparence depuis l'Accord de Paris: Le DROIT GLOBAL DE L'ENVIRONNEMENT COMME SOLFÈGE? .56

Anne-Sofie Tabau 
LA PROGRESSIVE HARMONISATION DES RÈGLES DU PROCÈS ENVIRONNEMENTAL: MANIFESTATION

DE L'ÉMERGENCE D'UN DROIT GLOBAL? ............................................................69

Eve Truilhé-Marengo

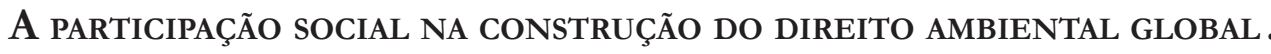
80 Michelle Lucas Cardoso Balbino

A PROTEÇÃo AMBIENTAL COMO EFEITO INDIRETO DO SISTEMA DE GESTÃo DE ENERGIA ISO 50001

Matheus Linck Bassani e Ricardo Serrano Osorio

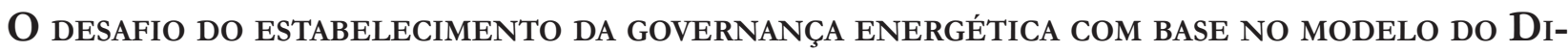
reito Administrativo Global: ESTUdo de CASO DAS ENERgias RENOVÁveis. 122 Alice Rocha da Silva

Othon Pantoja Oliveira de Azevedo

O PRINCÍPIO DA PARTICIPAÇÃo E A CRIAÇÃO E GESTÃo DAS ÁREAS PROTEGIDAS NA PERSPECTIVA DO DIREITO AMBIENTAL GLOBAI

Marcia Dieguez Leuzinger e Solange Teles da Silva

A teoria Ambientalista (GREen theOry) e a COMpetênCia CONSUltiva da CoRTE InTERAmericana de Direitos Humanos: O caso da Colômbia................................................. 148

Eduardo Biacchi Gomes e Ane Elise Brandalise

III. Artigos sobre outros temas....................................................... 160

30 anos do Protocolo de Montreal: Uma história de sucesso do Direito Ambiental

INTERNACIONAL 162

Fernando Rei e Valeria Cristina Farias

MinORIAS NACIONAIS, PROTEÇão INTERNACIONAL E TRANSNACIONALIDADE 182 Ana Maria D'Ávila Lopes e Luis Haroldo Pereira dos Santos Junior

Da relevância dos casos do Desarmamento Nuclear perante a Corte Internacional DE JUSTIÇA 203 Lucas Carlos Lima 
OS CONTROLES DE CONVENCIONALIDADE TRADICIONAL E INTERAMERICANO: INSTITUTOS DISTINTOS OU DUAS FACES DA MESMA MOEDA?

Gilberto Schäfer, Roger Raupp Rios, Paulo Gilberto Cogo Leivas e Jesus Tupã Silveira Gomes

EL SOFT LAW COMO FUENTE DEL DERECHO INTERNACIONAL: REFLEXIONES DESDE LA TEORÍA DE LA COMPLEJIDAD

Rafael Sanz e André Folloni

Ley de rotulación de alimentos de Chile: ¿'Traba comercial o protección de la saLUD?

Nicolás Cobo

IV. RESENHA DE LIVRO.

O CiVILIZAdor gentil das AmÉRICAS: CONSIDERAÇÕes EM TORNO DA OBRA THE HIDDEN HIStory of International LaW in the Americas: Empire and LeGal Networks, de Juan Pablo SCARFI 278

Cicero Krupp da Luz

'Mestizo International Law: A global intelectual history 1842 - 1933' De Autoría de Arnulf Becker-Lorca .283 Jimena Sierra-Camargo

América Latina em Continuidades e rupturas 287 Adriane Sanctis 


\title{
Ley de rotulación de alimentos de Chile: ¿Traba comercial o protección de la salud?*
}

\author{
Food Labeling Law of Chile: trade barrier to \\ trade or health protection?
}

Nicolás Cobo**

\section{RESUMEN}

Las políticas públicas para reducir el sobrepeso y la obesidad como pandemia encuentran en el etiquetado de alimentos una buena alternativa para decisiones nutricionales saludables. La ley N²0.606 de Chile, supone un desafío novedoso, aunque enfrenta dificultades en su implementación y objeciones por incumplir los compromisos internacionales del país con sus socios comerciales. Si afecta estándares de la OMC, el Acuerdo de Obstáculos Técnicos y el Codex Alimentarius, es una materia que se analiza a través de las observaciones de países en el Comité de Obstáculos Técnicos al Comercio (BTC) y la doctrina, debido a que el rótulo negro puede estigmatizar negativamente algunos alimentos, sin necesariamente existir una causalidad científica directa negativa en el consumo.

Palabras clave: Sobrepeso y alimentación, Etiquetado de alimentos, Obstáculos Técnicos al Comercio

\section{Abstract}

Public policies to reduce overweight and obesity as a pandemic, find on food labeling a good alternative for healthy nutritional decisions. Chile's law $\mathrm{N}^{\circ} 20,606$ is a novel challenge, although it faces difficulties in its implementation and objections to breaching the country's international commitments with its trading partners. Whether it affects WTO standards, the Technical Barriers to Trade Agreement and the Codex Alimentarius is an issue that is analyzed with comments from countries in the Committee Technical Barrier to Trade (TBT) and doctrine, since the black label may imply negatively stigmatizing some foods, without necessarily a direct scientific causation.

Keywords: Overweight and food, Food labeling, Technical Barriers to Trade

* Recebido em 10/02/2018

Aprovado em 18/02/2018

** NICOLÁs COBO ROMANí, es Doctor en Derecho de la Universidad de Salamanca, Magister Comercio Internacional Universidad de Barcelona; Director Escuela de Graduados Facultad de Derecho Universidad Católica, Profesor Derecho Internacional y miembro del Observatorio del Derecho a la Alimentación desde 2011.ncobo@uc.cl

\section{Planteamiento}

Se propone un análisis respecto de la pertinencia e implementación de una normativa muy novedosa de etiquetado de alimentos desarrollada en Chile, que lleva tan solo un año desde su entrada en vigencia y cuyos efectos preliminares, tanto respecto de su implementación, como del logro de los 
objetivos declarados de reducir los actuales niveles de sobrepeso y obesidad en los niños, se encuentran aún en etapa primaria de desarrollo. Lo anterior, mediante un análisis, sistematización, seguimiento y cumplimiento de la implementación de la ley $\mathrm{N}^{\circ} 20.606$ de etiquetado de alimentos de Chile. Asimismo, se propone un análisis crítico, a partir de la comparación de otras regulaciones de etiquetado de alimentos con formatos y objetivos similares, un análisis de las restricciones de comercialización y publicidad dirigida a menores, en base a las recomendaciones y estándares de organismos de salud, con un enfoque particular en la política de reducción de la obesidad y el sobrepeso y su vinculación con las normas de comercio internacional aplicables.

La hipótesis es que la información nutricional del etiquetado de alimentos de Chile cumple adecuadamente con los estándares y compromisos internacionales y con las obligaciones del país ante la OMC en sus diferentes acuerdos, en especial, el Acuerdo de Obstáculos Técnicos al Comercio, Medidas Sanitarias y Fitosanitarias y el Codex Alimentarius.

El esquema, formato y plazos para el etiquetado aprobado en Chile, mediante la ley $\mathrm{N}^{\circ} 20.606$, constituyen una normativa adecuada en el marco de los compromisos comerciales internacionales, justificado en los objetivos declarados por la autoridad de salud. Analizar los fundamentos, criterios y normas utilizados respecto de los parámetros internacionales en el Codex Alimentarius, formato e implementación relativos a los contenidos nutricionales, y ello no supone un incumplimiento de las obligaciones de no discriminar y se revisarán los planteamientos de los socios comerciales respecto de la nueva normativa en el Comité de Barreras Técnicas y sus efectos.

Se propone establecer, si la manera como se ha interpretado actualmente el derecho de conocer los nutrientes críticos de los alimentos, da cumplimiento adecuado de incluir información suficiente que permita una decisión libre y conducente a una nutrición saludable para los consumidores, considerando su formato y parámetros, en base a las recomendaciones y estándares internacionales de una alimentación adecuada y saludable y si las regulaciones podrían caber en el esquema del paternalismo libertario.

Analizar y evaluar el cumplimiento en la implementación de la ley $\mathrm{N}^{\circ} 20.606$ sobre etiquetado de alimentos, diferencias y semejanzas con normativas comparadas seleccionadas, su impacto y efectos en las obligaciones y las consecuencias ante eventuales incumplimientos, como también la fiscalización de la autoridad nacional. Se considera un análisis crítico del ajuste de la industria, sus costes estimados en esta etapa preliminar y los efectos iniciales.

La metodología a emplear será el método comparativo utilizando la dogmática del derecho, desde el contenido de las normativas jurídicas nacional y comparada, en especial, las normas comerciales internacionales pertinentes de la OMC y los acuerdos aplicables, confrontando diferencias y similitudes de normativas que incorporan rótulos de semáforos en países seleccionados por su semejanza, y con el aporte del análisis crítico de los principios de la doctrina, y de la jurisprudencia relevante, cuando sea pertinente.

\subsection{Contexto de obesidad y desafíos de salud pública}

Los malos hábitos alimenticios de las familias ha tendido al descuido de la calidad de la nutrición, el aumento del consumo de alimentos y bebidas ultraprocesados generan desafíos muy complejos para la salud pública, cerca de la mitad de los adultos (53,8\%) tienen sobrepeso u obesidad, según datos de la OCDE en $2015^{1}$. Ello se debe fundamentalmente a la disponibilidad de alimentación altamente calórica y el cambio de hábitos, en que el sedentarismo es la conducta preponderante.

Aunque el sobrepeso, hasta hace poco, estaba asociado a un problema de países desarrollados, la tendencia de los últimos años, muestra que hoy también está presente en países en desarrollo. En México, por ejemplo, con $72,5 \%$ de los adultos mexicanos y el $36,3 \%$ de los adolescentes $^{2}$, según $\mathrm{FAO}$ un $58 \%$ de personas tienen sobrepeso y la obesidad afectan al 23\% de la población de América Latina y el Caribe ${ }^{3}$, o como el caso de China, que en 2014, presentaba prevalencia de sobrepeso y obesidad con $17,2 \%$ (niños) y $9,11 \%$ (niñas). ${ }^{4}$

\footnotetext{
1 Health at a Glance 2015 OECD Indicators

2 Encuesta Nacional de Salud y Nutrición Ministerio de Salud de Chile 2016

3 Panorama de la Seguridad Alimentaria y Nutricional en América Latina y el Caribe FAO y OPS 2017

4 Trends in overweight and obesity among rural children and adolescents from 1985 to 2014 in Shandong, China Ying-xiu Zhang, Zhao-xia Wang, Jin-shan Zhao, Zun-hua Chu European Journal of Preventive Cardiology Vol 23, Issue 12, pp. 1314 - 1320; April-26-2016
} 
Según CEPAL ${ }^{5}$, al año 2.030 se proyectan 204 mil muertes en Chile por causa de obesidad. Chile ocupa el segundo lugar en obesidad después de México, asimismo, Chile es el principal consumidor de bebidas azucaradas $^{6}$. Algunos datos revelan la preocupante situación de salud en Chile: $25 \%$ de los alumnos de $8^{\circ}$ básico se encuentran en riesgo cardiovascular ${ }^{7}$. Desde el punto de vista económico, Chile gastaría un 0,5\% del PIB en obesidad, de hecho, entre 2005 y de acuerdo con el Ministerio de Salud de Chile en 2015 se duplicó el número de menores de 6 años con obesidad ${ }^{8}$.

Este creciente desafío, según el Institute for Health Metrics and Evaluation (IHME) , y la OMS ${ }^{10}$ afecta a 2 mil millones en el mundo, ello exige la exploración de medidas que reduzcan esta tendencia, y que van desde la prohibición, impuestos, educación y promoción de actividad física, entre otras. Dentro de estas acciones, también destacan las regulaciones del etiquetado de alimentos que incluyen información de las calorías, equivalentes de actividad física y guías alimenticias diarias (GDA). Los programas de alimentación escolar del gobierno de Chile (JUNAEB), están siendo revisados y modificados significativamente para evitar entregar dietas de baja calidad nutricional o excesivamente calóricas, como también un conjunto de acciones contra la obesidad infantil en el Programa Contrapeso ${ }^{11}$.

Los malos hábitos alimenticios requieren orientar la atención a los restaurantes de comida rápida, supermercados y tiendas de barrios, generándose por ello, normativas que adviertan e informen adecuadamente los componentes nutricionales. En 2008, comenzó la primera normativa voluntaria de información calórica en

5 Fernandez, Andrés et al. Impacto social y económico de la malnutrición Modelo de análisis y estudio piloto en Chile, el Ecuador y México; Comisión Económica para América Latina y el Caribe (CEPAL) 2017

6 Popkin B \& Hawkes C Sweetinf of the Global Diet, particularly beverages: patterns trens and policy responses The Lancet diabetes \& Endocrinology, Volume 4 Issue 2, 2016, 174- 186

7 Estudio Nacional de Educación Física Encuesta SIMCE en educación física, 2016

8 MINSAL octubre de 2016 Diario La Tercera 2 de octubre de 2016 http://www.latercera.com/noticia/menores-de-seis-anoscon-obesidad-se-duplican-durante-la-ultima-decada/

9 Global, regional, and national prevalence of overweight and obesity in children and adults during 1980-2013: a systematic analysis for the Global Burden of Disease Study 2013 Ng, Marie et al. The Lancet, Volume 384, Issue 9945, 766 - 781

10 http://www.who.int/mediacentre/factsheets/fs311/es/ (acceso el 4 de agosto de 2017)

11 http:// contrapeso.junaeb.cl/ (acceso el 4 de agosto de 2017) los menús en Nueva York ${ }^{12}$, para luego, en el año 2010 se aprobó una ley federal, haciendo obligatoria esta medida en restaurantes y cafeterías.

Los hábitos nutricionales y la relativa baja comprensión de los descriptores nutricionales ha centrado parte del debate en los etiquetados, su formato y contenido y la necesidad de advertir de manera más clara la calidad de los alimentos, dando al consumidor información nutricional de lo que se consume ${ }^{13}$.

Algunas preguntas que surgen de inmediato, son ¿cuál debe ser el rol del regulador ante los malos hábitos nutricionales, el creciente sedentarismo y sus consecuencias en la salud pública? ¿Se trata de una función informativa o debe el Estado asumir una tarea restrictiva y de limitar las decisiones de alimentación de los ciudadanos? ¿Qué formato o exigencia de etiquetado nutricional es aceptable o cuáles de éstos podrían implicar una eventual traba comercial?

Cuando se refiere a la alimentación de los menores de edad y en esferas de colegios, puede parecer más fácil nuestra respuesta, pero siempre está supeditada a la responsabilidad que tienen los padres y al rol formador que deben desempeñar los establecimientos escolares, en los adultos, las decisiones nutricionales libres e informadas.

\subsection{Etiquetado, formatos y eficacia}

Hay estudios que han medido la atención prestada a la información de las etiquetas, la que es muy breve, entre 25 y 47 segundos $^{14}$, se trata de entregar una información que sea simple, relevante en la decisión nutricional y transparente, es decir, entregar todo lo que sea sustantivo y no matizar o disfrazar algunos nutrientes para generar una expectativa errada de los beneficios o su inocuidad, evitando el uso de términos como "light" y otros similares que inducen a equívocos.

12 Harnack, L. J., \& French, S. A. (2008). Effect of point-ofpurchase calorie labeling on restaurant and cafeteria food choices: A review of the literature. The International Journal of Behavioral Nutrition and Physical Activity, 5, 51.

13 Burton, S., Creyer, E. H., Kees, J., \& Huggins, K. (2006). Attacking the Obesity Epidemic: The Potential Health Benefits of Providing Nutrition Information in Restaurants. American Journal of Public Health, 96(9), 1669-1675. http://doi.org/10.2105/ AJPH.2004.054973

14 Borgmeier, I., \& Westenhoefer, J. (2009). Impact of different food label formats on healthiness evaluation and food choice of consumers: A randomized-controlled study. BioMedCentral Public Health, 9, 184. doi:10.1186/1471-2458-9-184 
La Organización Mundial de la Salud y la Organización Panamericana de la Salud, en su Plan de Acción para la prevención y control de enfermedades no transmisibles de 2013-2019, recomiendan medidas para reducir el sobrepeso y obesidad, especialmente en niños a través de etiquetados de alimentos, como también normas y políticas sobre alimentos y bebidas, como también "proporcionar etiquetado nutricional en todos los alimentos preenvasados en los que se reivindiquen propiedades de carácter nutricional o sanitario" ${ }^{15}$.

El etiquetado nutricional pueden ser en base voluntario (como Dinamarca o Suecia) u obligatorio (como Corea o Chile), debe contener al menos 4 nutrientes (proteínas, carbohidratos, grasas, energía y cualquier otro nutriente que se haya requerido) ${ }^{16}$.

El etiquetado, en todo caso, no tiene una eficacia demostrada, ya que los consumidores han expresado que prestan escaza atención a los rótulos por distintas causas $^{17}$, como el bajo interés, la comprensión de la información, el tiempo de atención a su lectura y que se asigna mayor relevancia a otros aspectos como el valor, marca, fecha de vencimiento, el envase o la información del productor. Entre las alternativas, el formato de "semáforo" ha mostrado una eficacia en el cambio de conductas con un 18\% de mejora en las opciones saludables y una reducción de un $4 \%$ en el consumo de calorías ${ }^{18}$.

Hay indicios que los programas de reformulación de alimentos obligatorios son más exitosos que perspectivas de normativas voluntarias y que el uso de etiquetado en el frente del envase con semáforo múltiple es el más eficazmente empleado por los consumidores ${ }^{19}$, lo que hace pensar que debe ser la tendencia para implementar con plazos e incentivos adecuados y acompañamiento,

$15 N^{\circ} 32$ letra i, Plan De Acción Mundial Para La Prevención y el Control de las Enfermedades no Transmisibles 2013-2020 acuerdo del 15 de Marzo de 2013 Organización Mundial de La Salud.

16 CAC/GL 2_1985, revisado en 1993

17 Mandle, J., Tugendhaft, A., Michalow, J., \& Hofman, K. (2015). Nutrition labelling: a review of research on consumer and industry response in the global South. Global Health Action, 8.

18 Cecchini, M. and L. Warin (2016), "Impact of Food Labelling Systems on Food Choices and Eating Behaviours: A Systematic Review and Meta $\square$ analysis of Randomized Studies", Obesity Reviews, Vol. 17(3), pp. 201-210. , citado por Obesity Update 2017 OCDE www.oecd.org/health/obesity-update.htm (acceso 18 de agosto de 2017)

19 Kloss L. et al. (2015), "Sodium Intake and Its Reduction by Food Reformulation in the European Union - A Review", NFS Journal, Vol. 1, pp. 9-19 en algunos casos, incorporando la diferenciación del tipo y tamaño de la industria alimenticia.

\subsection{Experiencias Comparadas}

Existen distintas experiencias comparadas de etiquetados que promueven una alimentación saludable y que han recurrido al uso de íconos o logos con advertencias dentro del sistema frente del envase (FOP por sus siglas en inglés), como el caso de los semáforos en Ecuador ${ }^{20}$, o la pizza de colores en Australia, sin embargo, a diferencia del caso de Chile, éstos no presentan inquietudes sobre el potencial efecto negativo a la industria por el uso de esas etiquetas.

Las regulaciones de etiquetados que han implementado los países son muy diversas, tanto respecto de su obligatoriedad, como de los formatos que asumen, algunos han optado por el uso de semáforos (Ecuador o Reino Unido), que contiene información nutricional de alimentos (Guideline Daily Amounts) y otros emplean rótulos con advertencias, cuando existen altos contenidos en azúcar, sodio, grasas saturadas o calorías ${ }^{21}$. Ecuador advierte tres niveles de nutrientes alto, medio y bajo en azúcares, sodio y grasas, con los colores del semáforo, lo que parece muy claro para la información de consumo, sin por ello, implicar que se trata de un alimento dañino per se. México, por su parte, emplea otro sistema más confuso con 6 íconos basado en las porciones diarias y que no facilitan una decisión de consumo saludable, sin una compleja comparación.

En EEUU, la FDA en mayo de 2016²2, estableció la obligación de incluir en las etiquetas de cereales, barras de caramelos, y otros alimentos envasados que se venden en supermercados, debiendo explicitarse en ellos el azúcar añadido en los alimentos y, en su caso, si se trata

20 Ecuador: Reglamento Sanitario de Etiquetado de Alimentos Procesados Para el Consumo Humano (Acuerdo Ministerial 5103 del 29 de noviembre de 2013), en plena vigencia desde 2014. Con advertencia respecto de azúcar, sodio y grasas, estableciéndose algunas flexibilidades para productos como duty free y plazos ampliados y la posibilidad de utilizar stickers en los envases. Bolivia: desde 2016 con la Ley de Promoción de Alimentación Saludable N ${ }^{\circ} 775$ del 8 de enero de 2016 existe una norma que obliga a informar los contenidos de grasas, azúcares, sodio y químicos lo que incluye restricciones a la publicidad. La normativa establece el formato de semáforo para grasas, azúcares y sodio.

21 Beeken, Rebecca J and Wardle, Jane, Public beliefs about the causes of obesity and attitudes towards policy initiatives in Great Britain. Public Health Nutrition 2013 Dec; 16(12):2132-7

22 FDA-2012-N-1210-0875 
de azúcar natural o artificial. La recomendación supone reducir la ingesta de azúcares añadidos a menos del 10 $\%$ de las calorías diarias.

El caso de Reino Unido, desde 2013, la Food Standards Agency, estableció sistemas voluntarios de semáforo en el frente de envase (FOP), con etiquetas de color rojo, amarillo y verde, con la presencia de descriptores nutricionales como azúcares y grasas. Algunos países del norte de Europa usan formatos con un cerrojo (Suecia, Noruega y Dinamarca) y otros un símbolo en forma de corazón (Finlandia) ${ }^{23}$.

La Agencia de Normas Alimentarias del Reino Unido, utiliza un rótulo que informa sobre cinco nutrientes principales con un círculo de colores rojo, amarillo y verde (grasa, grasas saturadas, azúcares, sodio y energía). Sin embargo, se trata de un esquema en base voluntario y no de un etiquetado que se aplique transversalmente en la UE, ya que se consideró que estigmatizaba negativamente algunos alimentos como el jamón ibérico con categoría roja, por ello recibió la oposición de 7 de sus miembros $^{24}$, por estimarse que contradecía la normativa existente $^{25}$. Desde el año 2013, Australia y Nueva Zelan$\mathrm{da}$, implementaron sistemas basados en un ranking de estrellas de salud, aunque en un esquema voluntario ${ }^{26}$.

Existe evidencia internacional que muestra impactos positivos del etiquetado en mujeres o consumidores interesados en la información nutricional, sin embargo, se observa una baja comprensión de los contenidos, a veces, menor de la percibida, como en un caso de México, un $57 \%$ dijo entender los factores nutricionales, aunque en la realidad solo un 1,2\% respondió correctamente sobre éstos.

También existen aspectos que dificultan el objetivo esperado del etiquetado, ello debido a que la información es insuficiente, o incluso porque las categorías son

23 Capacci, S., Mazzocchi, M., Shankar, B., Brambila Macias, J., Verbeke, W., Pérez-Cueto, F. J., Kozioł-Kozakowska, A., Piórecka, B., Niedzwiedzka, B., D’Addesa, D., Saba, A., Turrini, A., Aschemann-Witzel, J., Bech-Larsen, T., Strand, M., Smillie, L., Wills, J. and Traill, W. B. (2012), Policies to promote healthy eating in Europe: a structured review of policies and their effectiveness. Nutrition Reviews, 70: 188-200. doi:10.1111/j.1753-4887.2011.00442.x

24 http://www.globalmeatnews.com/Retail/Seven-EU-statesoppose-British-traffic-light-labelling (acceso 4 de agosto de 2017)

25 Food Information Consumers Regulation 1169/2011

26 Zhang, Q., Liu, S., Liu, R., Xue, H., \& Wang, Y. (2014). Food Policy Approaches to Obesity Prevention: An International Perspective. Current Obesity Reports, 3(2), 171-182. http://doi. org/10.1007/s13679-014-0099-6 confusas en las decisiones individuales de consumo, lo que reduciría la eficacia del etiquetado calórico ${ }^{27}$.

Se pueden observar distintos formatos de etiquetado como los casos de Tablas de Información Nutricional; listado de nutrientes; semáforos en diversos formatos; sistema de puntuación nutricional; etiquetado de calorías; Guía de Cantidades Diarias (GDA): en cada caso, hay una unidad de referencia que puede variar (por porción; por cantidad diaria recomendada; por $\left.100 \mathrm{gr} / 100 \mathrm{~mL}^{28}\right)$. Los colores, tamaños y ubicación varían en cada legislación.

Todos los demás formatos de etiquetados que se han mencionado (Australia, Ecuador, Reino Unido, Dinamarca), tienen presentaciones menos estigmatizantes o negativas que el caso chileno y suponen un preponderante objetivo de informar y permitir una decisión nutricional adecuada. Los colores y sus textos no inducen a pensar que se estaría frente a un producto no saludable, sino que debe ser consumido moderadamente. El énfasis podría identificarse en que se espera que las políticas autónomamente puedan cambiar los hábitos contemporáneos de sedentarismo y mala nutrición, cuando se trata de una política integral, en que la educación y la promoción de hábitos saludables sean cotidianas. El resultado, parece ser que, se está dirigiendo la regulación, principalmente, afectan y modifican la oferta y no a la demanda, cuando se trata de menores de edad, podría ser más aceptable esta limitación.

\section{Ley N²0.606: el CAso de Chile}

En junio de 2016, originada en un proyecto del Senador Girardi ${ }^{29}$, comenzó a regir en Chile la ley N²0.606, la que estableció diversas restricciones en las etiquetas con un formato frente del envase (FOP), sobre la base de la elección de un criterio uniforme de base 100gr,

27 Kiszko, K. M., Martinez, O. D., Abrams, C., \& Elbel, B. (2014). The influence of calorie labeling on food orders and consumption: A review of the literature. Journal of Community Health, 39(6), 1248-1269

28 Government and voluntary policies on nutrition labelling: a global overview Corinna Hawkes, Independent Consultant, Food and Nutrition Policy, France http://www.fao.org/docrep/018/ i0576e/i0576e04.pdf (acceso 5 de agosto de 2017)

29 Moción de los señores Senadores Sergio Mariano Ruiz Esquide Jara, Guido Girardi Lavín, Carlos Ominami Pascual, Carlos Ignacio Kuschel Silva y Evelyn Matthei Fornet. Fecha 21 de marzo, 2007. Moción Parlamentaria en Sesión 5. Legislatura 355. 
con máximos de $275 \mathrm{kcal}$, 400mg de sodio 10 gr de azúcar y 4 gr de grasa. Respecto de los líquidos en $100 \mathrm{~mL}$ el tope de azúcares es de $5 \mathrm{gr} ; 70 \mathrm{kcal}, 100 \mathrm{mg}$ de sodio y 3 de grasa, si bien se trata de una medida estándar, no siempre se condice con el alimento respectivo y da información que puede inducir a errores. Asimismo, se establecieron en la ley limitaciones a la publicidad destinada a menores y también respecto de la venta de determinados productos dentro de establecimientos educacionales.

Algunos beneficios del sistema que plantea la ley $\mathrm{N}^{\circ}$ 20.606, son que su imagen es muy simple y visible, lo que supone una advertencia de un riesgo potencial, que aunque no puede asociarse al consumo directo, si puede implicar frente al consumo excesivo de esos alimentos, cuando tienen contenidos excesivos de sodio, azúcar, grasas o calorías. El rótulo simplificado de alimentos de Chile es único en el mundo por su claridad y ha sido reconocido por la OPS y FAO como una herramienta valiosa en la lucha por detener el avance la obesidad y "que acerca al consumidor a una mayor transparencia sobre los productos que consume" ${ }^{30}$.

La Ley se implementó a través de la modificación del Reglamento Sanitario de los Alimentos ${ }^{31}$ y que entró en vigencia un año después. Su objetivo central, es la protección de los niños y asegurar una información de los alimentos, favoreciendo una decisión informada y disminuir el consumo de alimentos altos en contenidos de calorías, grasas saturadas, azúcares y sodio ${ }^{32}$. Si bien la vigencia de la ley comenzó 12 meses después de su aplicación, su proceso de implementación demorará hasta 3 años, ya que las Pymes tienen un plazo especial de $36^{33}$ meses para ajustarse a los estándares del nuevo etiquetado. Del mismo modo, la ley incrementa la exigencia de los parámetros con una tabla que obliga a seguir reduciendo los niveles o deben mantenerse los rótulos.

30 http://www.paho.org/chi/index.php?option=com_content\& view $=$ article\&id $=636$ :respaldo-de-la-opsoms-y-fao-al-reglamentosanitario-de-los-alimentos-para-la-aplicacion-de-la-ley-20606-enchile\&Itemid $=1005$ (acceso 4 de agosto de 2017)

31 Decreto $\mathrm{N}^{\circ} 13$, publicado en el Diario Oficial el 26 de Junio de 2015

32 Boletín Ley de Etiquetado MINSAL http:/ / web.minsal.cl/leyde-alimentos-nuevo-etiquetado-de-alimentos/ (acceso 4 de agosto de 2017)

33 Decreto $\mathrm{N}^{\circ} 13$, art. 3

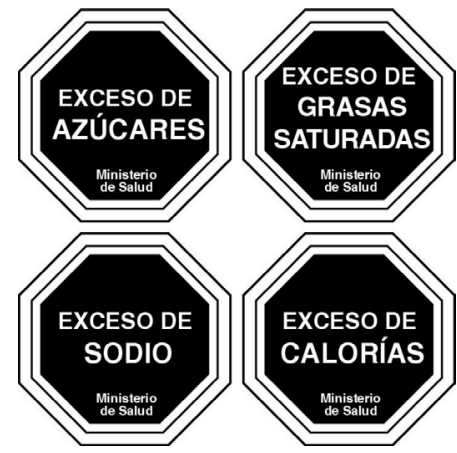

\begin{tabular}{|c|c|c|c|c|}
\hline $\begin{array}{c}\text { Lími- } \\
\text { tes }\end{array}$ & Azúcares & $\begin{array}{c}\text { Grasas } \\
\text { saturadas }\end{array}$ & Calorías & Sodio \\
\hline líquidos & $5 \mathrm{~g} / 100 \mathrm{~mL}$ & $3 \mathrm{~g} / 100 \mathrm{gr}$ & $70 \mathrm{Kcal} / 100 \mathrm{~mL}$ & $100 \mathrm{mg} / 100 \mathrm{gr}$ \\
\hline Sólidos & $10 \mathrm{~g} / 100 \mathrm{gr}$ & $4 \mathrm{~g} / 100 \mathrm{gr}$ & $275 \mathrm{Kcal} / 100 \mathrm{gr}$ & $400 \mathrm{~g} / 100 \mathrm{gr}$ \\
\hline
\end{tabular}

Elaboración propia con datos Reglamento Sanitario de Alimentos Dcto 977/96

Se han criticado algunos aspectos y matices de la implementación de esta ley, en particular, la falta de un énfasis en la educación nutricional, ya que "[...] se requiere enmarcarla en una política de Estado sólida, consistente en el tiempo, con participación de todos los sectores, muy especialmente de Educación. Si no educamos a la población en alimentarse en forma saludable, a pesar de esta ley, continuará la demanda por alimentos muy poco sanos", Dr. Fernando Vio ${ }^{34}$, considera este experto del INTA, que existe un enfoque insuficiente, con lo que hoy sucede en las escuelas.

Asimismo, se cuestiona que la ley no resuelva adecuadamente algunos problemas, ya que fija umbrales muy bajos por nutrientes críticos y, además, sin hacer una distinción entre alimentos y que tampoco se refiere a porciones ${ }^{35}$. También se criticó que el efecto de la normativa termina en la práctica siendo retroactiva, al aplicarse incluso a inventarios existentes en los supermercados, que habían sido envasados con anterioridad a la vigencia de la ley. Además, según enfatizaron algunos socios comerciales de Chile en el Comité de Barreras Técnicas o TBT (por sus siglas en inglés) que "[...] el Codex no estableció ningún umbral para los nutrientes a que se refiere la legislación chilena y las advertencias chilenas podrian arriesgar generar un estigma en algunos alimentos, cuyo consumo moderado forma parte de una dieta saludable". ${ }^{36 "}$

En cuanto a la eficacia de las etiquetas de la regulación chilena, ello se ha cuestionado y existe evidencia mixta, ya que sólo el 31\% de los chilenos dice que

34 Diario El Mercurio, 23 de junio de 2016

35 Editorial Diario La Tercera 3 de enero de 2017

36 https://www.wto.org/spanish/news_s/news13_s/ tbt_17jun13_s.htm Traducción propia (acceso 6 de agosto de 2017) 
acostumbra a leer el rotulado y el $37 \%$ admite que no entiende la información nutricional ${ }^{37}$. Solo un 35\% de los consumidores afirma que cambia la conducta ante los rotulados, a 4 meses de vigencia de la ley ${ }^{38}$ y, según ICEI de la U de Chile, un 56,2\% de los consumidores no compara los sellos entre productos ${ }^{39}$.

\subsection{Implementación de la ley y su fiscalización:}

Adicionalmente a los rótulos, la ley incluye una prohibición de los enganches publicitarios y juguetes ${ }^{40}$, quedando en todo caso abierto a la interpretación de la autoridad. La industria de alimentos sostiene que se trata de una interpretación muy estricta frente al tema de la publicidad, y se afectaría la propiedad intelectual de una marca ya registrada, por ello, "no podría el fiscalizador revisar la manera o forma o disposición de los elementos figurativos del envase de las empresas cuando estos ya han sido registrados como marca, pues ello sería una intervención a la competencia"41.

Polémico también, fue el caso de la prohibición de la venta del "Kinder Sorpresa" de la empresa Ferrero, debido a que la ley incluye una prohibición de los enganches para incentivar el consumo de alimentos para niños, quedando pendiente una acción ante organismos como la OMC, por considerar la empresa afectada que se trata de una traba comercial, la que no estaría justificada en los compromisos de la OMC.

La implementación de la ley fue objeto de varias evaluaciones, durante el primer año se llevaron a cabo 3.000 inspecciones en supermercados y distribuidoras ${ }^{42}$ de los cuales un 56,6\% fueron en establecimientos educacionales y $37,6 \%$ en supermercados y distribuidoras. Lo que implicó distintas infracciones $42,6 \%$ por el rotulado; $17,8 \%$ por publicidad dirigida a menores y $39,5 \%$ por venta en establecimientos educacionales. La mayor parte de los sumarios (91\%), terminaron en una amonestación y apercibimiento.

\footnotetext{
37 Adimark-Fundación Chile, 2014

38 Centro de Estudios del Retail (CERET) Universidad de Chile

39 Diario La Tercera; 5 de enero de 2017

40 art 110 bis, Decreto $N^{\circ} 977 / 96$

41 Diario Financiero, 28 de julio de 2017, pag 6

42 Informe de evaluación de la implementación de la ley sobre composición nutricional de los alimentos y su publicidad; Subsecretaría de Salud Pública División de Políticas Públicas Saludables y Promoción Departamento de Nutrición y Alimentos, Junio 2017
}

\subsection{Desafíos comerciales de la norma de etiquetado}

Hasta ahora, los países han procurado generar etiquetados en base a estándares con información que ha tendido a ser más comprehensiva y los consumidores exigen incluir elementos como la condición de ser orgánicos, si contienen productos transgénicos, la presencia de sustancias que puedan ser alergénicos (Gluten, Maní y otros) y, desde luego, elementos que faciliten una decisión saludable de la nutrición.

La necesidad de mejorar la nutrición y los hábitos de sedentarismo, para la comunidad internacional, como un objetivo deseable de política pública, está fuera de discusión. Sin embargo, lo que debe reflexionarse es hasta dónde puede llegar la regulación y la prohibición del Estado en las decisiones de consumo individual, si la educación e información son adecuadas y suficientes con dichos objetivos, o bien puede llegarse al uso de políticas que afecten la publicidad, la restricción de venta en algunos lugares para menores, e incluso a la prohibición de la oferta de productos que contengan juguetes. ¿Deben y pueden los gobiernos al regular materias de salud, también involucrarse en las decisiones de compra y alimentación de los ciudadanos, cuando se trate de alimentos no dañinos y en dosis de consumo moderado? ¿estaríamos ante un caso de paternalismo libertario?

La normativa chilena ha querido buscar en medidas más drásticas y que abarquen más allá de etiquetados visibles y de fácil comprensión, otras acciones que han generado dificultades en el ajuste a las empresas de alimentos, e incluso, la eventual imposición de trabas al comercio, por tratarse de medidas que estarían afectando los compromisos comerciales internacionales en acuerdos de la OMC, tales como Obstáculos Técnicos al Comercio (TBT), Medidas Sanitarias y Fitosanitarias (por sus siglas en inglés SPS), e incluso, los acuerdos sobre aspectos de derecho de propiedad (por sus siglas en inglés TRIPs).

Se afirma que el objetivo del etiquetado nutricional, es evitar una confusión al consumidor en su decisión de nutrición, y que muchas veces se le presentan alimentos como saludables (light), cuando no deberían ser calificados de esa manera o que su consumo excesivo pueda generar problemas futuros a la salud, esto último, supone generalmente altas y reiteradas ingestas y no se trata de alimentos que per sé, sean dañinos. 
Al mismo tiempo, se debe dar cumplimiento a los criterios establecidos en el Codex Alimentarius ${ }^{43}$, para la seguridad alimentaria, su inocuidad que aseguren que los alimentos no causarán daño a la salud, como también el respeto a las reglas del acuerdo de TBT.

En la práctica se realizaron intercambios de información por parte de Chile y ante las inquietudes de varios miembros, se generaron algunos ajustes en el proceso de implementación y la reducción de eventuales impactos negativos. Del mismo modo, el proceso debe realizarse sin causar un injustificado perjuicio a los productores, permitiéndose, además de un razonable periodo de ajuste en sus procesos productivos, información oportuna, adecuada y acompañamiento, permitiendo diferenciaciones para grandes y pequeñas empresas, lo que en los hechos fue expresamente considerado en el reglamento de la ley.

Otro elemento que nos parece más complejo de aceptar, aun adhiriendo los objetivos de salud invocados por la norma, es el daño a los derechos de propiedad y de imagen de la empresa de alimentos, ya que se prohibió el uso de imágenes que identifican los productos ${ }^{44}$, son algunos casos de imágenes afectados por restricciones de publicidad dirigida a menores. Podría afectar derechos ya reconocidos en la Ley 19.039 de Propiedad Industrial y en Acuerdo sobre los Aspectos de los Derechos de Propiedad Intelectual Relacionados con el Comercio (ADPIC).

La condición de tratarse de derechos de marca registrada no parece óbice para una acción restrictiva cuando se trata de algo que contenga probadamente causalidad directa y nociva para la salud, pero no siendo ese el caso, sino el potencial efecto ante un consumo en exceso, que nos parece que puede ser diferenciado el tratamiento.

La normativa incluye prohibiciones de realizar publicidad dirigida a niños menores de 14 años, de enganches o juguetes e incluso de venta en establecimientos educacionales, lo que ha generado importantes dificul-

43 CAC/GL 2-1985, Rev. 1 - 1993 Directrices Del Codex Sobre Etiquetado Nutricional; CAC/GL 23-1997 Directrices Para el uso de Declaraciones Nutricionales; CODEX STAN 1-1985, Rev. 1-1991 Norma General del Codex para el Etiquetado de los Alimentos Preenvasados; CAC/GL 23-1997 Directrices para el Uso de Declaraciones Nutricionales y Saludables.

44 Tales como: Estrellitas, Chocapic, Trix y Zucosos de Nestlé; Tigre Tony y Sam el Tucán de Kellog; o Cheetos y Gatolate de Pepsico tades comerciales para la industria ${ }^{45}$. Diferente perspectiva, nos parece que suponen las restricciones de publicidad en horarios y que sean dirigidas a menores de edad, parecen razonables.

Otro tipo de acciones, que nos parece de difícil evaluación, es el caso de alimentos que tradicionalmente han incluido un juguete, como el "Kinder Sorpresa" de Ferrero y conforman su calidad única e inseparable, si se trata de alimentos que dañan la salud deben ser prohibidos, sin embargo, si se trata de un daño consecuencial a un mal hábito alimenticio, por ello, parece necesario tener matices o indemnizar por los perjuicios. Se trata de un producto que no puede ajustarse a las exigencias de la norma, aunque no necesariamente tenga la entidad de un alimento nocivo, cosa que es cuestionada por el autor de la ley, Senador Girardi.

\subsection{Efectos y ajuste de la industria}

La industria estima asimismo, que ha gastado en Chile U\$21MM en el proceso de re etiquetado, cambio de diseño, nueva gráfica y pérdidas de etiquetas que ya no se pueden utilizar, otro costo asociado sería de U\$50MM, por productos que no alcanzaron a comercializarse antes de la fecha de vigencia de la ley, asimismo, existen costos adicionales por la reformulación de productos para ajustarse a los parámetros y así poder eliminar el rótulo negro ${ }^{46}$.

Es probable que ante las restricciones de etiquetado, sean las propias empresas de alimentos las que ya han iniciado sendos procesos de ajustes, algunos de ellos ya llevan años, según Mc Donalds, por ejemplo, comenzó en 2003 a reducir en 10\% los niveles de azúcares, en 2007 se incluyeron vegetales en las opciones de la Cajita Feliz, lo que posiblemente evitó ser afectadas por la prohibición de venta a niños menores de 14 años $^{47}$. Existe también evidencia preliminar que la industria tiene incentivos para ajustarse unilateralmente ante exigencia de etiquetado en el frente del envase, reformulando y reduciendo sus niveles ${ }^{48}$.

45 art. 110 bis Decreto Supremo 977 de 1996 modificado por Decreto 13 de 1995

46 Economía y Negocios, Diario El Mercurio 22 de mayo de 2017

47 Negocios Diario La Tercera, 11 de junio de 2017

48 Kloss L. et al. (2015), "Sodium Intake and Its Reduction by Food Reformulation in the European Union - A Review", NFS Journal, Vol. 1, pp. 9-19 
Esta tendencia ya se ha percibido en algunas empresas como Coca Cola, que realizaron ajustes unilaterales, esta compañía modificó en 24 meses 59 fórmulas y a 29 de ellas, según el Gerente General Dino Tironi, le rebajaron el contenido de azúcar ${ }^{49}$.

Estaríamos entonces ante una política que coincide con los postulados de Thaler y Sunstein, a través de "[...] intervenciones que preservan la libertad de los individuos, pero que pueden afectar a su comportamiento" 50 , al agregar información orientada a la salud y al mismo tiempo ofrecer un consejo se podría calificar como una política "paternalista" y "libertaria" y conformar un "nudge" o empujoncito, sin restringir la libertad del consumidor, "que está motivado por los límites cognitivos, prejuicios, rutinas y hábitos en los individuos y la toma de decisiones sociales que plantea barreras para las personas a realizarse en su propio interés declarado ${ }^{51}$ ", que se realiza, forzando la modificación de la oferta.

\section{BarRera TÉCNICA SEgÚN LOS COMPROMISOS ante OMC y Codex Alimentarius}

Las TBT pueden distinguirse y considerarse necesarias o no necesarias y, por ello, restrictivas al comercio, también se debe relacionar con otros acuerdos, como los temas sanitarios (SPS), en los casos que se refieran directamente con la seguridad alimentaria. Los acuerdos autorizan las medidas si protegen la salud, animales, medio ambiente, prevenir prácticas engañosas (etiquetado y envases) y no deben ser más restrictivas o de mayores plazos que lo necesario para el cumplimiento con las leyes nacionales ${ }^{52}$.

En concreto, debemos considerar si la información entregada por el país a sus socios comerciales fue oportuna, adecuada y con antecedentes de respaldo científico en el Comité de TBT.

¿Por qué esas opciones serían menos restrictivas al comercio que el caso chileno? Es algo que cabe pre-

49 Diario La Tercera, 4 de septiembre de 2016

50 http://elpaissemanal.elpais.com/confidencias/cass-sunstein/ (acceso 15 de Agosto de 2017)

51 The Definition of Nudge and Libertarian Paternalism: Does the Hand Fit the Glove? European Journal of Risk Regulation, 7(1), 155-174. (traducción propia)

52 https://www.wto.org/spanish/tratop_s/tbt_s/tbt_info_s. htm (acceso 4 de agosto de 2017) guntarse y observar las diferencias. Pareciera ser que la advertencia en formato de un octágono negro con un disco pare es, inequívocamente, algo negativo y que sin duda, advierte de un peligro, cosa que no sucede en los otros formatos que no están calificando o estigmatizando, ni llevan a pensar que se trata de un alimento nocivo en sí mismo. Existen otros formatos que facilitan la comparación respecto de los contenidos y sus excesos, al considerar el rótulo de la normativa chilena, la única posibilidad de comparación de productos similares es respecto del número de rótulos que tiene el envase.

Los Obstáculos Técnicos al Comercio (TBT), están sujetos a principios, como el que no se deben establecer obstáculos innecesarios; no ser discriminatorios, y en base de trato nacional, en efecto, el Acuerdo dispone que, "[...] con respecto a los reglamentos técnicos, se dé a los productos importados del territorio de cualquiera de los Miembros un trato no menos favorable que el otorgado a productos similares de origen nacional y a productos similares originarios de cualquier otro país" ${ }^{\prime 5}$. Asimismo, el principio de equivalencia, esto es, que al comparar los reglamentos técnicos se puede lograr el mismo objetivo; de transparencia, debiendo notificarse en 60 días antes de la adopción formal de los reglamentos técnicos y procedimientos de evaluación, cuando "pueda tener un efecto significativo en el comercio de otros Miembros ${ }^{54 "}$. Debe establecerse un servicio nacional de información para que los "miembros de la OMC pueden solicitar y obtener información y documentación sobre los reglamentos técnicos, normas y procedimientos de prueba adoptados o en proyecto en el país" ${ }^{55}$, y permitiendo las consultas en las reuniones del Comité de Obstáculos Técnicos.

Varios de los socios comerciales de Chile (México, Guatemala, Unión Europea, Argentina, Australia, Costa Rica, Colombia, Canadá y Suiza), expresaron sus inquietudes respecto de la normativa chilena de rotulación que es muy novedosa, y aunque comparten el objetivo de salud invocado, en diversas consultas señalaron su preocupación en cuanto a que las medidas decretadas sean compatibles con las obligaciones del Acuerdo de Obstáculos Técnicos al Comercio (TBT) y las de Propiedad Intelectual (TRIPs), toda vez que los acuerdos exigen

53 art 2.1 párrafo 1 del artículo 2 Acuerdo Obstáculos Técnicos al Comercio

54 párrafo 9 del artículo 2 y párrafo 6 del artículo 5 Acuerdo Obstáculos Técnicos al Comercio

55 https://www.wto.org/spanish/tratop_s/tbt_s/tbt_info_s. htm (acceso de agosto de 2017) 
que se deben asegurar los miembros no establecer obstáculos innecesarios al comercio internacional ${ }^{56}$ y que deben basarse en estándares relevantes ${ }^{57}$, del mismo modo, debe existir evidencia científica de respaldo que permita establecer un umbral, cuyo exceso genere un riesgo a la salud. $\mathrm{Y}$, en todo caso, que no se trate de un medio ineficaz o inapropiado ${ }^{58}$ de las normas o elementos pertinentes (art. 2.4), cuando se aleje de las normas internacionales como base de los reglamentos técnicos.

En este sentido, se deben tener presente las disposiciones del Codex Alimentarius y las directrices para el uso de declaraciones nutricionales saludables (CAC/GL 23-1997), las directrices sobre etiquetado nutricional (CAC/GL 2-1985) y la directrices sobre declaraciones de propiedad que podrán inducir a errores (CAC/GL 1-1979). El Codex, sin embargo, no establece normas expresas respecto del etiquetado frontal, lo que dificulta el estándar y deja abierta a la interpretación.

En el Comité de Barreras Técnicas al Comercio y en la gestación del proyecto en junio de 2013, varios países expresaron su preocupación por el riesgo de estigmatización de algunos alimentos que pueden ser consumidos moderadamente, sin que por ello, se genere algún problema a la salud.

La jurisprudencia del Órgano de Apelación de la OMC, ha señalado que no deben establecerse reglamentos técnicos que tengan por objeto o efecto crear obstáculos innecesarios al comercio y que para "quedar comprendido en la definición de "reglamento técnico", el documento debe aplicarse a un producto o grupo de productos identificable, debe establecer una o más características del producto ${ }^{59}$, y "la observancia de las caracte-

56 art 2.2 Acuerdo Obstáculos Técnicos al Comercio

57 art 2.4 Acuerdo Obstáculos Técnicos al Comercio

58 "En consecuencia, en el contexto del párrafo 4 del artículo 2 un medio ineficaz significa un medio que no cumple la función necesaria para alcanzar el objetivo legítimo perseguido, mientras que un medio es inapropiado cuando no es especialmente idóneo para el logro de ese objetivo. ... La cuestión de la eficacia se refiere a los resultados de los medios utilizados, mientras que el carácter de apropiado atañe más bien a la naturaleza de esos medios. (las cursivas figuran en el original)" T.4.4.1 CE - Sardinas, párrafo 285 (WT/ $\mathrm{DS} 231 / \mathrm{AB} / \mathrm{R})$

https://www.wto.org/spanish/tratop_s/dispu_s/repertory_s/index_article_s.htm\#tbt (acceso 18 de agosto de 2017)

59 La esencia de la definición de "reglamento técnico" es que en un "documento" se han de "establecer" (es decir, enunciar, estipular o disponer) las "características de un producto". El término "características" tiene una serie de sinónimos que son útiles para entender el sentido corriente de ese término en este contexto. Así, las "características" de un producto incluyen, en nuestra opinión, cuales- rísticas del producto debe ser obligatoria" ". Si la normativa en comento, cumple o no con el criterio de una regulación técnica que no afecten las obligaciones ante la OMC, es algo que está siendo debatido, aunque hasta ahora, no se conocen consultas solicitadas hayan iniciado el sistema de solución de diferencias.

Un reglamento técnico, a diferencia de una norma, es aquel que incluye el etiquetado, es un "[d] ocumento en el que se establecen las características de un producto o los procesos y métodos de producción con ellas relacionados, con inclusión de las disposiciones administrativas aplicables, y cuya observancia es obligatoria' ${ }^{71}$. ${ }^{2}$ Podría, en todo caso, incluir las caracte-

quiera "calidades", "atributos", "peculiaridades" u otras "marcas distintivas" de un producto que sean objetivamente definibles. Tales "características" pueden referirse, en particular, a la composición, tamaño, forma, color, textura, dureza, resistencia a la tensión, inflamabilidad, conductividad, densidad o viscosidad de un producto. En la definición de "reglamento técnico" que figura en el punto 1 del Anexo 1, el propio Acuerdo OTC da ciertos ejemplos de "características de un producto": "prescripciones en materia de terminología, símbolos, embalaje, marcado o etiquetado". Estos ejemplos indican que las "características de un producto" incluyen no sólo las peculiaridades y calidades intrínsecas del propio producto, sino también características conexas tales como los medios de identificación, la presentación y la apariencia del producto. Además, según la definición del punto 1 del Anexo 1 del Acuerdo OTC, un "reglamento técnico" puede incluir las "disposiciones administrativas aplicables" a los productos que tengan ciertas "características". Por otra parte, observamos que en la definición de "reglamento técnico" se dispone que tal reglamento "también puede incluir prescripciones en materia de terminología, símbolos, embalaje, marcado o etiquetado $[\ldots]$ o tratar exclusivamente de ellas" (sin cursivas en el original). El empleo en esa frase del término "exclusivamente" y de la conjunción disyuntiva "o" indica que un "reglamento técnico" puede limitarse a establecer solamente una o unas pocas "características de un producto". T.4.1.1 CE - Amianto, párrafo 67 (WT/DS135/AB/R) https://www.wto.org/spanish/tratop_s/ dispu_s/repertory_s/index_article_s.htm\#tbt (acceso 18 de agosto de 2017)

60 T.4.1.6 CE — Sardinas, párrafos 175-176 Ver (WT/DS231/ $\mathrm{AB} / \mathrm{R})$

"Esta definición la interpretamos en el asunto CE - Amianto [párrafos 66-70]. Al hacerlo describimos tres criterios que debe cumplir un documento para quedar comprendido en la definición de "reglamento técnico" que figura en el Acuerdo OTC. Primero, el documento debe aplicarse a un producto o grupo de productos identificable. No obstante, el producto o grupo de productos identificable no tiene que estar expresamente identificado en el documento. Segundo, el documento debe establecer una o más características del producto. Estas características del producto pueden ser intrínsecas o pueden estar relacionadas con él. Las características se pueden prescribir o imponer de forma afirmativa o negativa. Tercero, la observancia de las características del producto debe ser obligatoria." https://www.wto.org/spanish/tratop_s/dispu_s/repertory_s/index_article_s.htm\#tbt (acceso 18 de agosto de 2017)

61 Anexo 1 Acuerdo sobre Obstáculos Técnicos al Comercio.

62 VER T.4.1.1 CE — Amianto, párrafo 67 (WT/DS135/AB/R) 
rísticas del producto de modo afirmativo o negativo. ${ }^{63}$ Aun está pendiente el debate respecto de si la mención "alto en" daría cumplimiento o puede generar una imagen negativa, que bien podría no ajustarse a los compromisos internacionales.

Los socios comerciales de Chile han expresado en los procesos de consultas, que consideran más conveniente y armónico con el comercio, el uso de advertencias de riesgos en el consumo excesivo y las campañas de salud, que las medidas anunciadas en la normativa chilena.

Según el Codex, las declaraciones deben evitar las expresiones respecto de propiedades de los alimentos que puedan suscitar dudas sobre la inocuidad de alimentos análogos, suscitar o provoca miedo a los consumidores $^{64}$.

Las declaraciones nutricionales deben ser consistentes con las políticas nacionales de salud y ser monitoreadas, las directrices de declaraciones nutricionales y saludables nos pueden dar luces sobre criterios rectores, deben estar "apoyadas por una cantidad de evidencia cientifica válida y suficiente como para justificar las declaraciones, proveer información verídica y no engañosa para ayudar al consumidor a elegir dietas saludables, y ser apoyadas por una educación especifica para el consumidor." "'. En el mismo sentido, cuando los alimentos incluyan nutrientes menos saludables deben incorporar iguales criterios para orientar e informar a los consumidores para una decisión de una dieta saludable.

Nos parece que, en lo fundamental, los principios se han respetado en la norma chilena, siendo debatible el que se pueda lograr los mismos fines mediante otros reglamentos técnicos. En las consultas realizadas en el Comité de Barreras Técnicas, los socios comerciales de Chile, expresaron que existían alternativas más amisto-

63 "Las "características de un producto" pueden, en nuestra opinión, prescribirse o imponerse con respecto a los productos de forma afirmativa o negativa. En otras palabras, el documento puede disponer, afirmativamente, que los productos han de tener ciertas "características", o el documento puede disponer, negativamente que los productos no han de tener ciertas "características". En ambos casos, el resultado jurídico es el mismo: en el documento "se establecen" ciertas "características" vinculantes para los productos, en un caso afirmativamente y en otro por implicación negativa". T.4.1.3 CE Amianto, párrafo 69 (WT/DS135/AB/R) https://www.wto.org/ spanish/tratop_s/dispu_s/repertory_s/index_article_s.htm\#tbt (acceso 18 de agosto de 2017)

64 Sección 3.5 CAC/GL 1-1979

65 Preámbulo del CAC/GL 23-1997 sas con el comercio para cumplir con mismos objetivos de salud, como las campañas de promoción y generar mayor conciencia ${ }^{66}$ se cuestionó, del mismo modo, que podría tratarse de advertencias demasiado alarmistas y que no estaban basadas en datos científicos o normas internacionales reconocidas. ${ }^{67}$

El objetivo declarado en el preámbulo del acuerdo del TBT, es de no crear obstáculos innecesarios al comercio, asegurando que los reglamentos técnicos y normas, incluidos los requisitos de envase y embalaje, marcado y etiquetado, y los procedimientos de evaluación estén en conformidad con los parámetros y criterios en base no discriminatoria, "[p] ara garantizar que los reglamentos y normas técnicas, incluidos los requisitos de embalaje, marcado y etiquetado y los procedimientos de evaluación de la conformidad con las reglamentaciones y normas técnicas, no crean obstáculos innecesarios al comercio internacional' ${ }^{3}$.

Es por todo ello, especialmente relevante, la crítica planteada por miembros de la OMC en cuanto la "existencia de normativa internacional de referencia, contenida específicamente en el Codex Alimentarius, sobre indicaciones nutricionales de los alimentos que serviría para los fines perseguidos por Chile, pero resultando menos lesiva." ${ }^{69}$, lo que supondría un incumplimiento de las obligaciones ante el acuerdo de TBT.

La diferencia entre el acuerdo de barreras técnicas TBT y de medidas sanitarias SPS es que, en "el Acuerdo TBT busca asegurarle al consumidor la entrega de información sobre su calidad técnica, es decir, no exclusivamente sanitaria, mientras que las SPS previenen riesgos cuya evaluación se sustenta en principios cientificos y no sólo en una eventual necesidad de informar al mercado"70, la evaluación del riesgo, por lo tanto, es propia del ámbito sanitario y no de las barreras técnicas.

En cuanto al régimen al cual deben entenderse las exigencia de estándares, ello dependerá de si deben ser

66 Reunión de junio 2013 del Comité Barreras Técnicas al Comercio de la OMC

67 Noticias OMC 18 y 19 de junio de 2014 https://www.wto. org/spanish/news_s/news14_s/tbt_18jun14_s.htm\#stc (acceso el 4 agosto de 2017)

68 Petros C. Mavroidis and Robert Wolfe, 2017 (tradución propia) 69 Boza, Sofía y Espinoza, Macarena; La Regulación Chilena sobre etiquetado y publicidad de los alimentos como instrumento contra la obesidad; Puentes Vol. 17 N 8, 16 de noviembre de 2016 pag 3

70 Sepúlveda Cristian, Manual para el Exportador Cómo entender y usar mejor los Acuerdos Comerciales, Cámara de Comercio de Santiago (CCS) y Dirección General de Relaciones Económicas. Internacionales - DIRECON. 2007 pag 47 
materia del acuerdo de medidas sanitarias SPS o bien de barreras técnicas al comercio TBT " $[\mathrm{e}] n$ la medida en que una norma se ocupa de la inocuidad de los alimentos, la sanidad animal o la sanidad vegetal, debería estar comprendida en el acuerdo SPS y, en la medida en que se refiere a cuestiones más "agregadas", como las etiquetas, debe caer bajo el acuerdo de TBT ${ }^{\prime 71}$ Hasta ahora, el debate con los socios comerciales se ha mantenido en el ámbito comercial y no de la salud, cuando es el fondo de la discusión del etiquetado.

La manera de lograr la conformidad de las normas nacionales cuando se aparten de los estándares y recomendaciones de las organizaciones internacionales y, sin que por ello, supongan un incumplimiento de las obligaciones de los miembros de la OMC, debe reunir determinadas condiciones ${ }^{72}$ :

Debe responder a objetivos legítimos ${ }^{73}$; ello supone que las normas internacionales sean ineficaces o inapropiados para los objetivos invocados; la medida sea proporcional y necesaria y la menos restrictiva posible al comercio; y la evaluación de los riesgos se base en información científica y técnica disponible.

Ya se ha advertido que hubo diversas expresiones de preocupación por parte de miembros de la OMC, ante las regulaciones de etiquetado chilena, por causa de protección a la salud, se presentaron inquietudes comercia-

71 Petros C. Mavroidis And Robert Wolfe; World Trade Review (2017), 16: 1, 1-24 (traducción propia)

72 Mozzoni Agustina, La no inclusión del etiquetado frontal en la normativa del Codex Alimentarius como obstáculo para el avance de un marco regulatorio nacional más protectorio del derecho a la salud; Revista Administración Pública y Sociedad No2 diciembre de 2016

73 "[..] De la interpretación del Grupo Especial surgen dos consecuencias. En primer lugar, la expresión "objetivos legítimos", del párrafo 4 del artículo 2, como estableció el Grupo Especial en su conclusión, debe abarcar los objetivos mencionados expresamente en el párrafo 2 del mismo artículo, a saber: "los imperativos de la seguridad nacional; la prevención de prácticas que puedan inducir a error; la protección de la salud o seguridad humanas, de la vida o la salud animal o vegetal, o del medio ambiente". En segundo lugar, teniendo en cuenta el empleo de la expresión "entre otros" en el párrafo 2 del artículo 2, los objetivos que abarca la expresión "objetivos legítimos" del párrafo 4 del mismo artículo se extienden más allá de la lista de los específicamente mencionados en el párrafo 2. Por otra parte, compartimos la opinión del Grupo Especial de que la segunda parte del párrafo 4 del artículo 2 implica que se debe examinar y determinar la legitimidad de los objetivos de la medida" T.4.4.2 CE — Sardinas, párrafo 286 (WT/DS231/AB/R) https://www.wto.org/spanish/tratop_s/ dispu_s/repertory_s/index_article_s.htm\#tbt (acceso 18 de agosto de 2017) les ante el Comité OTC de OMC en junio de $2014^{74}$, las que se referían a esta preocupación.

Chile notificó a sus socios comerciales en el Comité de Barretas Técnicas, la modificación de sus normas de etiquetado, publicidad y restricciones de venta se refieren a un rubro que EEUU estimó en U\$255MM anuales $^{75}$, asimismo las medidas estuvieron disponibles para comentarios en los meses de marzo y abril de 2013, luego de lo cual, se realizaron ajustes de la normativa original propuesta y se extendieron los plazos iniciales de vigencia.

Las inquietudes expresadas frente a las notificaciones (agosto de 2014 y Julio de 2015), fueron respecto de 12 Estados, aunque los comentarios más significativos fueron por parte de EEUU, que basaron su inquietud en el excesivo porcentaje abarcado de la superficie del envase, la que luego se ajustó desde un $20 \%$ original al $7,5 \%$ definitivo. EEUU también consideró la ausencia de necesidad y la falta de explicaciones sobre la aplicación de la normativa respecto del comercio en algunos alimentos, por ello, se realizaron presentaciones escritas con las preocupaciones de poder afectar el comercio, como también, de los plazos y su obligatoriedad. Para este país, las medidas podían implicar barreras innecesarias al comercio, existiendo alternativas para los legítimos objetivos de salud pública, enfatizando que, un bajo consumo de los mismos productos no genera problemas a la salud y además que los plazos de implementación eran muy restrictivos ${ }^{76}$. El escalonamiento de su aplicación fue considerado muy acelerado para permitir un adecuado ajuste de la industria alimenticia.

Otra consecuencia de las consultas desarrolladas en el Comité, fue que se redujeron las categorías de alimentos a las que se aplicarían las restricciones (como yogurt y pan), confirmándose por las autoridades de salud chilenas que no se aplicaría a los restaurantes y aclarando cómo sería el proceso de ajuste para productos previamente envasados.

México ${ }^{77}$, por su parte, expresó sus dudas en cuanto

74 https://www.wto.org/spanish/news_s/news14_s/tbt_18jun14_s. htm (acceso 18 de agosto de 2017)

752013 y 2014 Report on Technical Barriers to Trade, USTR

76 Minuta del Comité de Barreras Técnicas febrero de 2014 G/ $\mathrm{TBT} / \mathrm{M} / 61$

77 México tiene asimismo un programa de Estrategia Nacional para la Prevención y el Control del Sobrepeso, la Obesidad y la Diabetes, el cual contiene una política de etiquetado en el Reglamento de Control Sanitario de Productos y Servicios, y el reglamento téc- 
a que estas medidas cumplieran con los principios de las regulaciones técnicas (transparencia, proporcionalidad, base científica, y conformidad con los estándares), como también, una eventual violación de los acuerdos de propiedad intelectual (TRIPs), solicitando la revisión y modificación de normas y el uso de instrumentos que fueran menos restrictivos. Se podrían afectar obligaciones establecidas en el reglamento atentarían contra las disposiciones del art 17, Anexo 1C del acuerdo de Marrakech, "ya que las excepciones deben tener en cuenta los intereses legitimos de los titulares de las marcas actualmente registradas en nuestro país, derechos que son de rango constitucional, lo que en la especie no ocurre, despojando a la marca de su atributo principal, el cual dice relación con su distintividad ${ }^{8 \% "}$ y afectándose por ello, según Opazo la posibilidad de distinguir los bienes y servicios ofrecidos por las empresas.

Para México las regulaciones propuestas no estaban en conformidad con las exigencias del Codex Alimentarius, en cuanto a que llevaba a los consumidores a pensar que existe un conocimiento cuantitativo exacto de lo que se debe consumir para la mantener la salud, y no una comprensión respecto de los nutrientes en los productos y que una delimitación cuantitativa para los individuos no era válida, ya que no existe un modo objetivo en que el conocimiento de los requisitos individuales sea utilizado en el etiquetado ${ }^{79}$.

Brasil estimó como fuente de inquietud, los parámetros utilizados para la determinación de un producto como no saludable y que las medias no se basarían en las recomendaciones de las guías alimentarias de la OMS, en particular, le parecía preocupante la prohibición de venta en colegios y que podría conformar una infracción del Codex CAC/GL 1-1979 sección 3.5, ya que levanta dudas o genera miedo al consumidor ${ }^{80}$.

Hay varios elementos que debemos tener en consideración, comenzando por la evaluación del riesgo ${ }^{81} \mathrm{y}$ el principio precautorio ${ }^{82}$ que se ha invocado en la protección de la salud, sin embargo, nos parecen insuficiente

nico NOM- 051-SCFI/SSA1-2010, Especificaciones generales de etiquetado para alimentos y bebidas no alcohólicas preenvasadosInformación comercial y sanitaria.

78 Opazo Luis Felipe, http://www.elmercurio.com/Legal/Noticias/Opinion/2017/07/26/Ley-de-etiquetado-al-limite.aspx (acceso 25 de agosto de 2017)

79 Sección 2.2.3.10 G/TBT/M/70 17 de febrero de 2017

80 Sección 2.2.2.20 Minuta del Comité de Barreras Técnicas febrero de $2014 \mathrm{G} / \mathrm{TBT} / \mathrm{M} / 61$

81 art.5.1 Acuerdo Medidas Sanitarias y Fitosanitarias

82 art.5.7 Acuerdo Medidas Sanitarias y Fitosanitarias en este caso, ya que no existe evidencia de un daño y causalidad directa con demostración de base científica que permita aplicar las restricciones, el caso Carne de Hormonas, es claro en el requisito de demostrar sobre base científica, "una relación racional entre la medida y la evaluación del riesgo" dencia principal de a opinión científica ${ }^{84 ”}$ y que debe basarse en evaluaciones del riesgo que se hayan tenido en cuenta ${ }^{85}$.

\section{Conclusiones}

Es claro que el etiquetado por sí sólo, es insuficiente para modificar conductas y hábitos tan arraigados en la vida contemporánea, por lo que se requieren intervenciones multicausales y no restringirse exclusivamente a los rótulos de los envases, sino también, incluir información en los menús en restaurantes y colegios.

Los socios comerciales han planteado que se trata de medidas no amistosas con el comercio y que los objetivos de salud declarados se podrían lograr con otras alternativas. Lo que se ha podido observar hasta ahora, es que la industria tiene fuertes incentivos para generar ajustes unilaterales de modo de reducir los nutrientes que exceden los parámetros de la ley de etiquetado, para así evitar que se afecte la demanda en productos alimenticios en que ello sea posible. Sin embargo, no ha dejado de ser un proceso complejo y oneroso por lo que implica: reetiquetados, la existencia de inventarios aun sin vender, las condiciones que han impuesto otros actores, como los supermercados, que fijan plazos menores a la ley para eliminar productos o modificar las etiquetas. Lo habitual es que la fecha de producción del alimento es la que debe primar, más que la entrada en vigencia de la ley, lo anterior añadió un problema y coste adicional a la industria de alimentos.

Otros casos comparados, previos a la vigencia de la ley chilena, parecen diferenciarse, ya que advertían me-

83 para 192 Órgano Apelación WT/DS26/AB/R y WT/DS48/ AB/R DS26: Comunidades Europeas - Medidas que afectan a la carne y los productos cárnicos (hormonas) $\mathrm{OMC}$

84 para 193 Órgano Apelación WT/DS26/AB/R y WT/DS48/ AB/R DS26: Comunidades Europeas - Medidas que afectan a la carne y los productos cárnicos (hormonas) OMC

85 para 188 Órgano Apelación WT/DS26/AB/R y WT/DS48/ AB/R DS26: Comunidades Europeas - Medidas que afectan a la carne y los productos cárnicos (hormonas) OMC 
diante el uso de otros rótulos como semáforos u otros indicadores menos alarmantes y que facilitan la comparación y una decisión informada de consumo. Los otros rótulos cumplen mejor con el objetivo de informar y advertir a los consumidores. Si los rótulos negros producen un efecto negativo y de inducir a la percepción que son alimentos nocivos, es algo que se ha discutido con ímpetu y cuyos efectos se verán con el tiempo.

Nos parece que aquí estaría el centro del problema de la política pública en comento, en el posible efecto de incumplir los compromisos de las normas TBT, ya que va más allá de lo necesario para informar al consumidor y termina afectando a los productores de alimentos. Todo alimento consumido en exceso puede generar alguna externalidad negativa, y no por ello se trata de un alimento no saludable. La carga de la prueba está en el lado del regulador y no es probable que pueda demostrar una causalidad directa, en casos de una ingesta moderada. El daño a la imagen y marcas registradas de las empresas alimenticias sin duda se ven perjudicadas y deberían ser compensados por este daño.

Creemos empero, que los socios comerciales se han mantenido expectantes y aunque hay preocupación de países como México y EEUU, entre otros, la mayoría enfrenta el mismo desafío de la obesidad y el sobrepeso, pero hasta ahora los resultados de otras acciones de política pública como educación, promoción de actividad física, restricciones, impuestos, guías alimentarias e incluso la rotulación, han sido insuficientes ya que se trata de un cambio de hábito, por ello, se han puesto las esperanzas en la normativa chilena que podría ofrecer datos interesantes, ya no tanto desde los consumidores, sino desde los productores que con el objetivo de ajustarse a las exigencias de la nueva norma, y que sus productos sean más saludables han rebajado los nutrientes que exceden los parámetros fijados por la ley.

Respecto de las restricciones al uso de imágenes en las acciones publicitarias habituales respecto de las marcas que permitan identificar un producto de otro, tales como el uso de figuras, nos parece que se deberían respetar. En todo caso, aun si aceptásemos las prohibiciones de imagen, ello supondría un acto expropiatorio para las empresas y debe ser compensado por el Estado.

El objetivo que podemos anticipar y, que ya se advierte en algunos casos comentados, es que la industria se está ajustando y, consecuencialmente, con ello mejorará la nutrición en la ingesta, mas no necesariamente los hábitos de los consumidores a través de la información. Este cambio, que es sin duda algo positivo, se está realizando mediante la posible transgresión de algunas normas, que hasta ahora están siendo toleradas por los países que han expresado su preocupación en las instancias de la OMC, pero no conocemos que se hayan iniciado procesos de consultas conducentes al establecimiento formal de una disputa.

\section{Bibliografía}

Anne Marie Thow, Alexandra Jones, Corinna Hawkes, Iqra Ali, Ronald Labonté; Nutrition labelling is a trade policy issue: lessons from an analysis of specific trade concerns at the World Trade Organization. Health Promot Int 2017 daw109. doi: 10.1093/heapro/daw109

Björn Schildberg; Physikalisch-Technische Bundesanstalt How are Technical Barriers to Trade treated in EU Trade Arrangements? Recommendations for the Development Friendly Design of EPA Negotiations related to Technical Barriers to Trade 2011

Burton, S., Creyer, E. H., Kees, J., \& Huggins, K. (2006). Attacking the Obesity Epidemic: The Potential Health Benefits of Providing Nutrition Information in Restaurants. American Journal of Public Health, 96(9), 16691675. http://doi.org/10.2105/AJPH.2004.054973

Cardwell Michael; The UK Agri-Food Sector, Brexit and International Trade: Opportunities and Challenges http:/ / foodresearch.org.uk/2017/01/the-uk-agri-food-sector-brexit-and-international-trade-opportunitiesand-challenges/

Carreno, I. (2016). An Update on Nutrient Profiles in Light of the Dextro Energy Judgment of the EU General Court. European Journal of Risk Regulation (EJRR) 7(3), 588-596.

Cecchini, M. and L. Warin (2016), "Impact of Food Labelling Systems on Food Choices and Eating Behaviours: A Systematic Review and Meta-analysis of Randomized Studie", Obesity Reviews, Vol. 17(3), pp. 201-210.

Food Security and Safety by Nutan Kaushik, Shilpanjali Deshpande Sarma, Harpreet Kaur, Swati Mitechelle Dsouza, Swati Tomar, and Anjali Parasnis pp 149-180 People, Planet and Progress Beyond 2015 Editor: P G Dhar Charkrabarti 
Gregg, E. W., \& Shaw, J. E. (2017). Global Health Effects of Overweight and Obesity.

Informe de evaluación de la implementación de la ley sobre composición nutricional de los alimentos y su publicidad; Subsecretaría de Salud Pública División de Políticas Públicas Saludables y Promoción Departamento de Nutrición y Alimentos, Junio 2017 http://web. minsal.cl/wp-content/uploads/2017/05/InformeImplementaci\%C3\%B3n-Ley-20606-junio-2017-PDF. pdf

Kloss, L. et al. (2015), "Sodium Intake and Its Reduction by Food Reformulation in the European Union A Review", NFS Journal, Vol. 1, pp. 9-19.

Moens, G. A. (2015). Improving Public Health through Behavioural Rules: A Legitimate Legislative Project?. Procedia-Social and Behavioral Sciences, 211, 1096-1105.

Mozzoni Agustina, La No Inclusión Del Etiquetado Frontal En La Normativa Del Codex Alimentarius: Un Posible Obstáculo Para Una Regulación Nacional Más Protectoria Del Derecho A La Salud; Revista Administración Publica y Sociedad N² diciembre de 2016 Instituto de Investigación y Formación en Administración
Pública https://revistas.unc.edu.ar/index.php/APyS/ article/view/15422

Rimpeekool, W., Seubsman, S., Banwell, C., Kirk, M., Yiengprugsawan, V., \& Sleigh, A. (2015). Food and nutrition labelling in Thailand: a long march from subsistence producers to international traders. Food Policy, 56, 59-66. http://doi.org/10.1016/j.foodpol.2015.07.011

Smyth, S., Kerr, W., \& Phillips, P. Labeling Demands, Coexistence and the Challenges for Trade. Journal of Agricultural \& Food Industrial Organization, 15(1).

Yahir Acosta Comentario Sobre Estados Unidos - Atún II (México), Informe del Órgano de Apelación; Revista de Derecho Económico Internacional Vol. 3 No. 2, Junio 2013

Trade Perspectives Issue Number 16: 11th September 2015 http://www.fra tinivergano.eu/en/trade-perspectives/issue-number-16-11 th-september-2015/

Wang, Y., Wang, L., Xue, H., \& Qu, W. (2016). A Review of the Growth of the Fast Food Industry in China and Its Potential Impact on Obesity. International Journal of Environmental Research and Public Health, 13(11), 1112. 
Para publicar na Revista de Direito Internacional, acesse o endereço eletrônico www.rdi.uniceub.br ou www.brazilianjournal.org.

Observe as normas de publicação, para facilitar e agilizar o trabalho de edição. 